Case Report

\title{
Neuroendocrine Differentiation in Breast Cancer: Clinicopathological Significance of Bcl-2 Positive Solid Papillary Carcinoma
}

\author{
Yoichiro Okubo, ${ }^{1}$ Takuji Okubo, ${ }^{2}$ Yoshimi Okubo, ${ }^{3}$ and Takao Ishiwatari ${ }^{4}$ \\ ${ }^{1}$ Department of Pathology, Kanagawa Cancer Center, 2-3-2 Nakao, Asahi-Ku, Yokohama, Kanagawa 241-8515, Japan \\ ${ }^{2}$ Department of Internal Medicine, Okubo Internal Medicine/Surgery Clinic, 1282 Ohaza, Oita, Oita Prefecture 870-1151, Japan \\ ${ }^{3}$ Department of Surgery, Okubo Internal Medicine/Surgery Clinic, 1282 Ohaza, Oita, Oita Prefecture 870-1151, Japan \\ ${ }^{4}$ Department of Pathology, Chiba Cytopathological Center, 5-27-8 Nishifuna, Funabashi, Chiba 273-0031, Japan
}

Correspondence should be addressed to Yoichiro Okubo; yoichiro0207@hotmail.com

Received 17 August 2016; Revised 22 November 2016; Accepted 24 November 2016

Academic Editor: Gottfried J. Locker

Copyright (C) 2016 Yoichiro Okubo et al. This is an open access article distributed under the Creative Commons Attribution License, which permits unrestricted use, distribution, and reproduction in any medium, provided the original work is properly cited.

\begin{abstract}
Solid papillary carcinoma (SPC) is considered a rare malignant breast tumor. Maluf and Koerner first reported this disease entity as a special type of ductal carcinoma in situ with several characteristic histopathological features, including low-grade cellular atypia, intracellular or extracellular mucin deposition, and solid papillary growth pattern, as well as neuroendocrine differentiation. The present paper describes a case of SPC with bcl-2 expression, which is known as a marker for malignancy of neuroendocrine tumors. Interestingly, despite bcl-2 expression being a poor prognostic indicator of neuroendocrine tumors, the patient with this tumor has achieved long-term survival (approximately 6 years) at the time of writing this report. Because previous investigators reported that bcl-2 expression might play a role in the inhibition of the development of breast cancer, we suggest that bcl-2 expression might reflect a good prognosis in patients with SPC, rather than being a poor prognostic indicator, as it is in several types of neuroendocrine tumor. However, to confirm this hypothesis, further investigation is required.
\end{abstract}

\section{Introduction}

Solid papillary carcinoma (SPC) is considered a rare malignant breast tumor, with an incidence ranging from $1.1 \%$ to $1.7 \%$ of all malignant breast tumors [1-10]. Maluf and Koerner first reported this disease entity as a special type of ductal carcinoma in situ (DCIS) with several characteristic histopathological features, including low-grade cellular atypia, intracellular or extracellular mucin deposition, and solid papillary growth pattern, as well as neuroendocrine differentiation [2]. Furthermore, the 2010 World Health Organization (WHO) classification categorized this tumor as a solid papillary carcinoma (ICD-O codes: $8509 / 2$ or $8509 / 3$, with and without invasion) and indicated that solid neuroendocrine carcinoma originated from SPC [11]. The present paper describes a case of SPC with low Ki-67 labeling index, absence of p53 expression, and bcl-2 expression, which is known as a marker for malignancy of neuroendocrine tumors [12-20].

\section{Case Presentation}

A 62-year-old Japanese woman presenting with a mass in the left breast was admitted to Japanese hospital for evaluation of this lesion. Mammography showed a high-density mass, and breast ultrasonography showed well-demarcated, highly abundant blood flow and a cystic lesion (Figure 1). Because these results indicated the presence of a malignant tumor, fine-needle aspiration cytology and needle biopsy were performed. Aspiration cytology indicated a lesion suspicious for carcinoma (Figure 2). If tumor cells show ill-defined rosette formation, these findings indicate solid papillary carcinoma. But actually this is not $100 \%$ proven. We therefore conducted needle biopsy that suggested ductal carcinoma. Consequently, the patient underwent partial mastectomy of the left breast with lymph node dissection. Our patient's surgical intervention had a successful outcome-neither local recurrence nor distant metastasis occurred, and she 


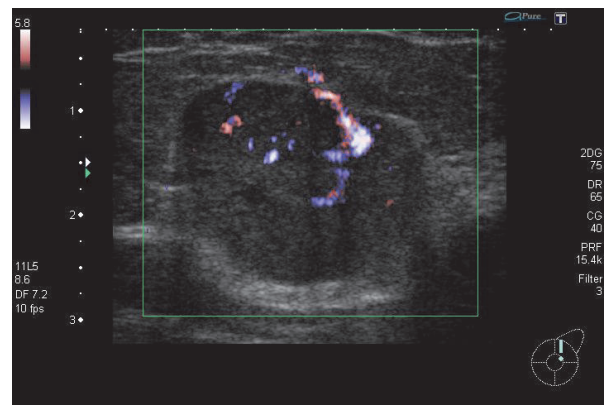

Figure 1: A breast ultrasonography image shows well-demarcated, highly abundant blood flow and a cystic lesion. These findings suggest a breast tumor with malignancy.

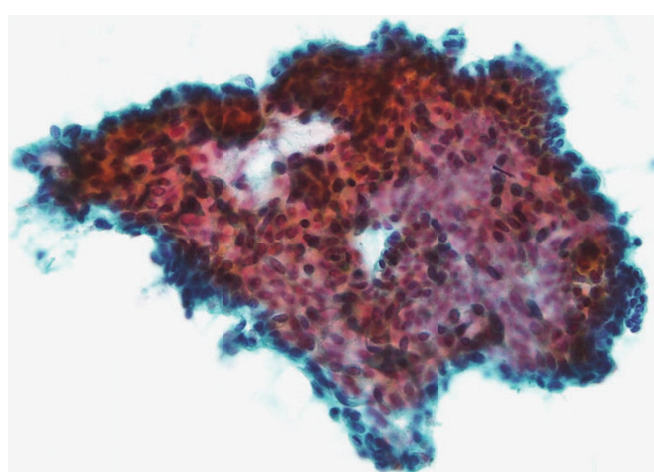

(a)

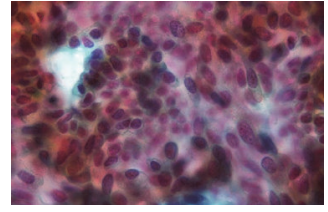

(b)

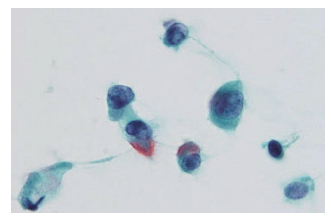

(c)

Figure 2: (a) Tumor cells form a papillary and conglomerate mass. Individual tumor cells have a round to short spindle-shaped nucleus with granular chromatin (Papanicolaou stain, original magnification $\times 400$ ). (b) Individual tumor cells have a round to short spindle-shaped nucleus with granular chromatin. Nuclear atypia is not prominent. Some tumor cells show ill-defined rosette formation (Papanicolaou stain, original magnification $\times 1000$ ). (c) Some tumor cells remain as separate cells rather than forming a mass. Many of these tumor cells contain cytoplasmic mucin. There are no prominent nucleoli (Papanicolaou stain, original magnification $\times 1000$ ).

maintains a high quality of life 70 months after the operation.

The surgical specimens, resected breast tissue and lymph nodes, were fixed in $10 \%$ buffered formalin. A solid tumor $25 \times 30 \times 25 \mathrm{~mm}$ in size and sharply demarcated from the surrounding tissue was visible at the cut surface of the breast tissue (Figure 3). Both necrosis and hemorrhage were present. Sections of paraffin-embedded tissue were prepared and stained with hematoxylin and eosin (HE) stain for light microscopic observation. Histological examination revealed intraductal carcinoma showing a solid papillary growth pattern and nuclear palisading around fibrovascular cores (Figure 3). The neoplastic lesion was encapsulated by bands of dense fibrosis. The tumor cells had a round to elongated and hyperchromatic nucleus plus finely granular eosinophilic cytoplasm. Intracellular and extracellular mucin deposition was present (Figure 4). Neither lymphovascular involvement nor lymph node metastasis was present.

Various monoclonal antibodies were used to evaluate the tumor cells immunohistochemically, including antisynaptophysin, chromogranin A, estrogen receptor (ER), progesterone receptor $(\mathrm{PgR})$, human epidermal growth factor receptor 2 (HER-2), bcl-2, p53, and Ki-67 antibodies. The tumor cells showed positive immunoreactivity for synaptophysin, chromogranin A, ER, PgR, and bcl-2 (Figures 5 and 6) and negative (or almost negative) immunoreactivity for HER-2. The Ki-67 labeling index was 3.7\% and almost negative or weak immunoreactivity for p53 was found (Figures 5 and 6). In the present study, representative antibodies against the following were then used via immunohistochemically evaluating the tumor cells: bcl-2 (1:50 dilution; Dako Japan, Tokyo, Japan, Clone name: 124), chromogranin A (1:800 dilution; Dako Japan, Clone name: DAK-A3), Ki-67 (1:200 dilution; Dako Japan, Clone name: MIB-1), and synaptophysin (1:40 dilution; Dako Japan, Clone name: M0776).

\section{Discussion}

Although SPC was first reported by Maluf and Koerner in 1995 [2], this disease entity remains underrecognized by clinicians, cytotechnologists, and pathologists [1]. As previously mentioned, the 2010 WHO classification categorized this tumor as a solid papillary carcinoma. It is well known that SPC usually arises in the seventh or eighth decade and has a better prognosis than other breast cancers [11]. Histopathologically, the tumor cells show a solid papillary growth pattern, nuclear palisading around fibrovascular cores, and a round to elongated nucleus plus finely granular 


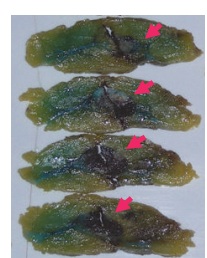

(a)

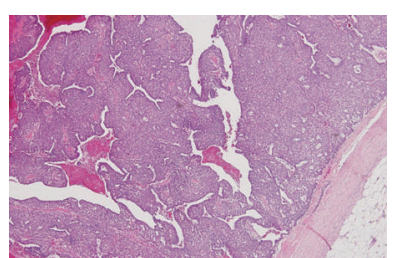

(b)

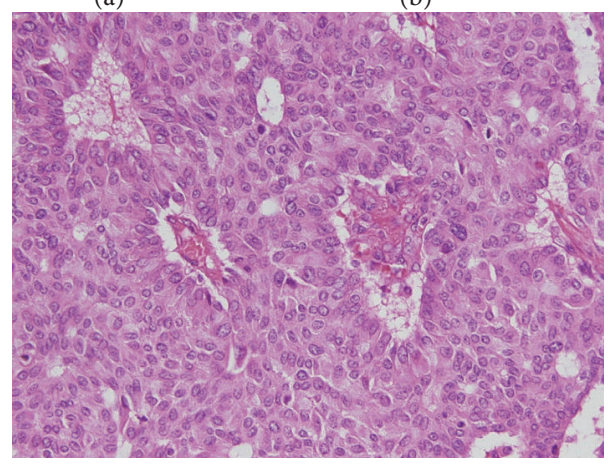

(c)

Figure 3: (a) A solid tumor $25 \times 30 \times 25 \mathrm{~mm}$ in size whose surface is sharply demarcated from the surrounding tissue (arrow) is seen at the cut surface of the specimen. Both necrosis and hemorrhage are present. (b) Sections of paraffin-embedded tissue were prepared and stained with HE double stain for light microscopic observation. A histological section reveals intraductal carcinoma showing a solid papillary growth pattern and the neoplastic lesion is encapsulated by bands of dense fibrosis (HE stain, original magnification $\times 40$ ). (c) Nuclear palisading around fibrovascular cores was found (HE stain, original magnification $\times 400$ ).

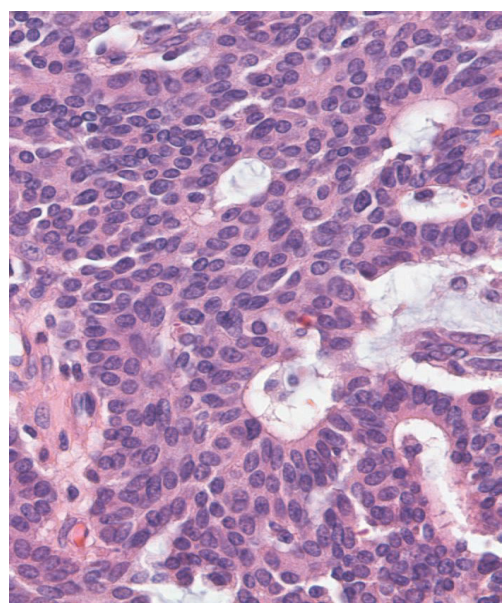

(a)

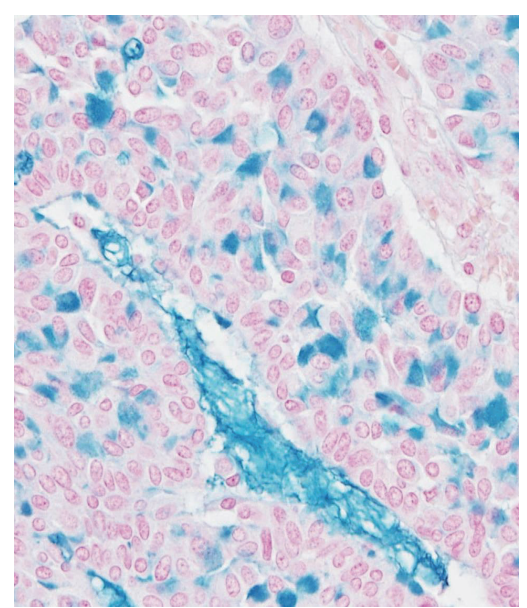

(b)

FIGURE 4: (a) The tumor cells have a round to elongated and hyperchromatic nucleus plus finely granular eosinophilic cytoplasm. In addition, rosette formation is seen (HE stain, original magnification $\times 400$ ). (b) Intracellular and extracellular mucin deposition (focal distribution) is present (Alcian blue stain, original magnification $\times 400)$.

eosinophilic cytoplasm [1]. Immunohistochemically, tumor cells usually show positive reactivity for neuroendocrine markers, including synaptophysin and chromogranin A. In addition, these tumors generally show positive reactivity for ER and PgR [1]. Several types of low-grade ductal carcinomas should be considered as differential diagnoses for SPC. In particular, papillary carcinoma is similar to SPC in many respects. Namely, it arises in elderly patients, grows in large well-circumscribed ducts, and is characterized by a good prognosis [5]. However, this tumor differs from SPC by the presence of delicate papillae, a branching pattern, a cuboidal to columnar appearance of the tumor cells, and the lack of a solid growth pattern $[5,11]$. Certain benign intraductal tumors should be considered because of their solid or papillary intraductal epithelial growth pattern $[5,11]$. However, a uniform cell population, increased mitotic activity, nuclear palisading around fibrovascular cores, and intracellular or extracellular mucin deposition are not usually seen in benign intraductal tumors $[5,7,11]$. Furthermore, the importance of the confirmation of neuroendocrine differentiation has 


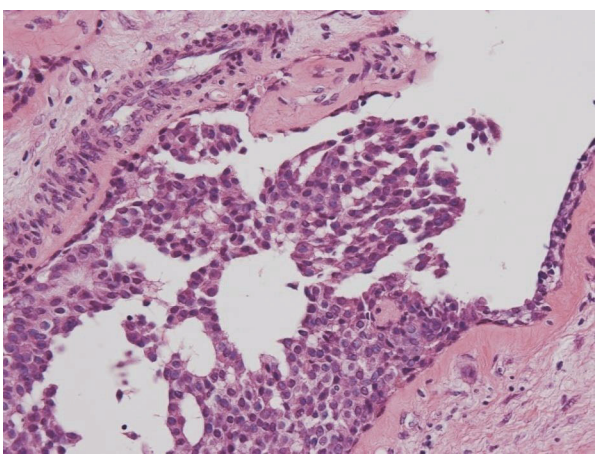

(a)

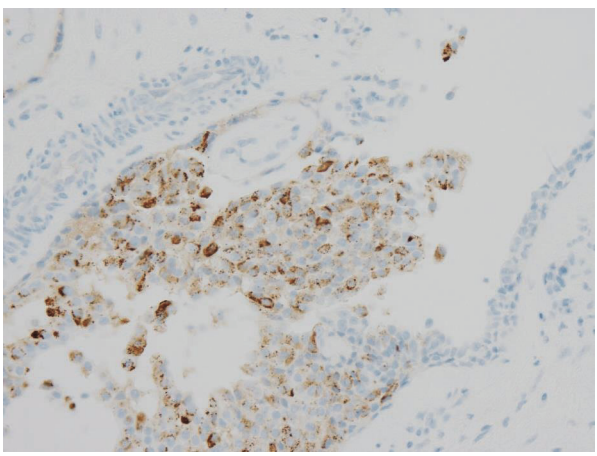

(c)

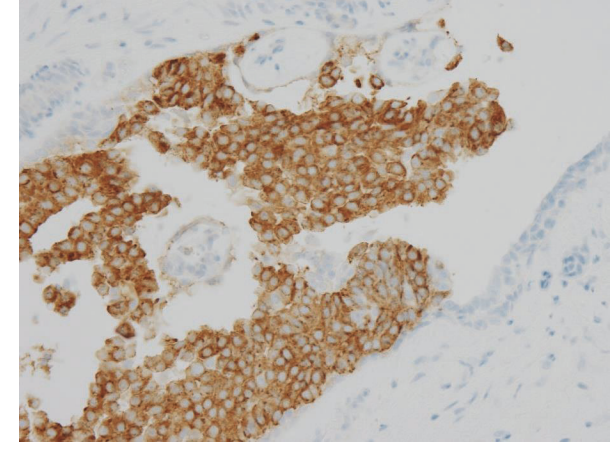

(b)

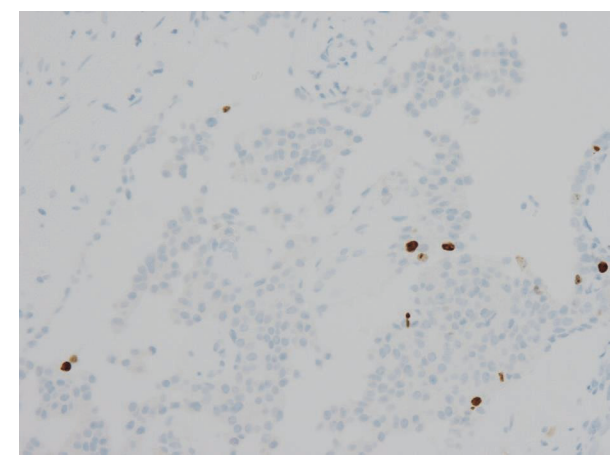

(d)

Figure 5: (a) The tumor cells show a solid papillary growth pattern (HE stain, original magnification $\times 400$ ). (b) The tumor cells show positive immunoreactivity for synaptophysin (Immunohistochemistry, original magnification $\times 400$ ). (c) The tumor cells show positive immunoreactivity for chromogranin A (Immunohistochemistry, original magnification $\times 400$ ). (d) A few tumor cells show positive immunoreactivity for Ki-67 (Immunohistochemistry, original magnification $\times 400$ ).

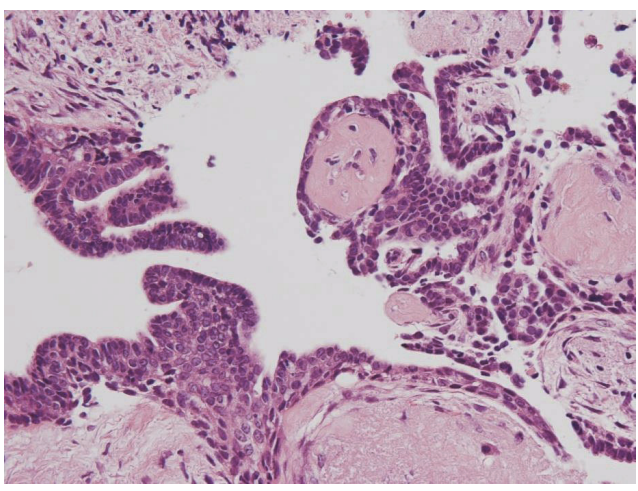

(a)

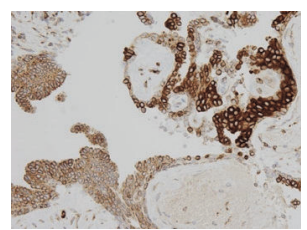

(b)

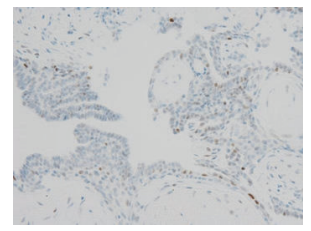

(c)

FIGURE 6: (a) The tumor cells show papillary growth pattern and nuclear palisading around fibrovascular cores (HE stain, original magnification $\times 400$ ). (b) The tumor cells show positive immunoreactivity for bcl-2 (Immunohistochemistry, original magnification $\times 400$ ). (c) A few tumor cells weakly show positive immunoreactivity for p53 (Immunohistochemistry, original magnification $\times 400$ ). (d) A few tumor cells show positive immunoreactivity for Ki-67 (Immunohistochemistry, original magnification $\times 400$ ).

often been described [5]. In the present paper, the tumor cells followed the characteristic features of SPC, including a solid papillary growth pattern, nuclear palisading around fibrovascular cores, a round to elongated and hyperchromatic nucleus, finely granular eosinophilic cytoplasm, and intracellular or extracellular mucin deposition, as well as positive reactivity for synaptophysin, but without positive reactivity for chromogranin A.

The immunohistochemical examination findings of this tumor are worthy further discussion. Ki-67 is known as a prognostic indicator of neuroendocrine tumors [12, 17, 21, 22]. Kawasaki et al. reported that the Ki-67 labeling 
index of nonneuroendocrine DCIS (8.1\%) was significantly higher than that of neuroendocrine DCIS (4.3\%), and they concluded that a low Ki-67 labeling index is correlated with a good prognosis in patients with neuroendocrine DCIS [20]. In fact, our patient showed an exceptionally low Ki-67 labeling index (3.7\%). In addition, several studies on neuroendocrine tumors have reported that bcl-2 or p53 expression might be correlated with malignant behavior [13-17, 19, 2327]. However, no studies were found in which investigation was limited to SPC. Therefore, we tried to establish the immunohistochemical prognostic indicators of SPC by using bcl-2 and p53, which are acceptable prognostic indicators in several types of neuroendocrine tumor. As a result, the tumor cells showed negative reactivity for $\mathrm{p} 53$, which may reflect a good prognosis in patients with SPC. However, the tumor cells showed positive reactivity for bcl-2, which is a poor prognostic indicator of neuroendocrine tumors [17].

To explain this paradoxical result, we considered the meaning of bcl-2 expression in breast cancer. Won et al. reported that beclin-1 and bcl-2 expression might play a role in the inhibition of the development of breast cancer [28]. Therefore, we suggested that bcl-2 expression also reflexes the good prognosis of the patients with SPC rather than prognostic indicators in several kinds of neuroendocrine tumor. Unfortunately, our immunohistochemical examinations are based on only one patient with SPC. To confirm this hypothesis, further investigation is required.

\section{Competing Interests}

The authors declare that there is no conflict of interests regarding the publication of this paper.

\section{Acknowledgments}

This work was supported by a Grant-in-Aid for Scientific Research to Yoichiro Okubo (no. 26860774) from the Ministry of Education, Culture, Sports, Science, and Technology of Japan and a research grant to Yoichiro Okubo from the Kanagawa Cancer Center (no. 28-27).

\section{References}

[1] N. Kuroda, N. Fujishima, K. Inoue, M. Ohara, K. Mizuno, and G.-H. Lee, "Solid papillary carcinoma of the breast: imprint cytological and histological findings," Medical Molecular Morphology, vol. 43, no. 1, pp. 48-52, 2010.

[2] H. M. Maluf and F. C. Koerner, "Solid papillary carcinoma of the breast: a form of intraductal carcinoma with endocrine differentiation frequently associated with mucinous carcinoma," American Journal of Surgical Pathology, vol. 19, no. 11, pp. 12371244, 1995.

[3] C. M. Quinn and J. L. Ostrowski, "Solid papillary carcinoma of the breast," The American Journal of Surgical Pathology, vol. 21, no. 2, pp. 256-258, 1997.

[4] O. Zekioglu, Y. Erhan, M. Çiriş, and H. Bayramoglu, "Neuroendocrine differentiated carcinomas of the breast: a distinct entity," Breast, vol. 12, no. 4, pp. 251-257, 2003.

[5] H. Nassar, H. Qureshi, N. V. Adsay et al., "Clinicopathologic analysis of solid papillary carcinoma of the breast and associated invasive carcinomas," The American Journal of Surgical Pathology, vol. 30, no. 4, pp. 501-507, 2006.

[6] Y. Okubo, O. Motohashi, N. Nakayama et al., "The clinicopathological significance of angiogenesis in hindgut neuroendocrine tumors obtained via an endoscopic procedure," Diagnostic Pathology, vol. 11, no. 1, p. 128, 2016.

[7] J. T. Rabban, F. C. Koerner, and M. F. Lerwill, "Solid papillary ductal carcinoma in situ versus usual ductal hyperplasia in the breast: a potentially difficult distinction resolved by cytokeratin 5/6," Human Pathology, vol. 37, no. 7, pp. 787-793, 2006.

[8] O. Robak, P. K. S. Lakatos, A. Bojic et al., "Influence of different oxygenator types on changing frequency, infection incidence, and mortality in ARDS patients on veno-venous ECMO," International Journal of Artificial Organs, vol. 37, no. 11, pp. 839846, 2014.

[9] N. Worel, P. Knöbl, G. Karanikas et al., "Hepatic dysfunction contributes to coagulation disturbances in patients undergoing whole body hyperthermia by use of extracorporeal circulation," The International Journal of Artificial Organs, vol. 37, no. 9, pp. $1-12,2014$.

[10] J. D. Coyne, "Invasive solid papillary breast carcinoma with papillary metastasis," Histopathology, vol. 50, no. 4, pp. 515-516, 2007.

[11] Y. Otsuki, M. Yamada, S.-I. Shimizu et al., "Solid-papillary carcinoma of the breast: clinicopathological study of 20 cases," Pathology International, vol. 57, no. 7, pp. 421-429, 2007.

[12] Y. Okubo, T. Yokose, M. Tuchiya et al., "Duodenal gangliocytic paraganglioma showing lymph node metastasis: a rare case report," Diagnostic Pathology, vol. 5, no. 1, article no. 27, 2010.

[13] A. A. Gal, M. N. Sheppard, J. D. L. Nolen, and C. Cohen, "p53, cellular proliferation, and apoptosis-related factors in thymic neuroendocrine tumors," Modern Pathology, vol. 17, no. 1, pp. 33-39, 2004.

[14] R. R. de Krijger, E. Van der Harst, F. Van der Ham et al., "Prognostic value of $\mathrm{p} 53$, bcl-2, and c-erbB-2 protein expression in phaeochromocytomas," Journal of Pathology, vol. 188, no. 1, pp. 51-55, 1999.

[15] I. S. Cadden, A. B. Atkinson, B. T. Johnston et al., "Cyclooxygenase-2 expression correlates with phaeochromocytoma malignancy: evidence for a Bcl-2-dependent mechanism," Histopathology, vol. 51, no. 6, pp. 743-751, 2007.

[16] D. A.-G. Wang, C. F. Johnston, J. M. Sloan, and K. D. Buchanan, "Expression of bcl-2 in lung neuroendocrine tumours: comparison with p53," Journal of Pathology, vol. 184, no. 3, pp. 247-251, 1998.

[17] T. N. Moyana, J. Xiang, A. Senthilselvan, and A. Kulaga, "The spectrum of neuroendocrine differentiation among gastrointestinal carcinoids: importance of histologic grading, MIB-1, p53, and bcl-2 immunoreactivity," Archives of Pathology and Laboratory Medicine, vol. 124, no. 4, pp. 570-576, 2000.

[18] U.-F. Pape, U. Berndt, J. Müller-Nordhorn et al., "Prognostic factors of long-term outcome in gastroenteropancreatic neuroendocrine tumours," Endocrine-Related Cancer, vol. 15, no. 4, pp. 1083-1097, 2008.

[19] B. S. Erler, M. M. Presby, M. Finch et al., “CD117, Ki-67, and p53 predict survival in neuroendocrine carcinomas, but not within the subgroup of small cell lung carcinoma," Tumor Biology, vol. 32, no. 1, pp. 107-111, 2011.

[20] T. Kawasaki, S. Nakamura, G. Sakamoto et al., "Neuroendocrine ductal carcinoma in situ (NE-DCIS) of the breast-comparative 
clinicopathological study of 20 NE-DCIS cases and 274 nonNE-DCIS cases," Histopathology, vol. 53, no. 3, pp. 288-298, 2008.

[21] Y. Okubo, T. Nemoto, M. Wakayama et al., "Gangliocytic paraganglioma: a multi-institutional retrospective study in Japan," BMC Cancer, vol. 15, no. 1, article 269, 2015.

[22] Y. Okubo, M. Wakayama, T. Nemoto et al., "Literature survey on epidemiology and pathology of gangliocytic paraganglioma," BMC Cancer, vol. 11, article no. 187, 2011.

[23] K. Fukutake, T. Ishiwatari, H. Takahashi et al., "Investigation of ossification in the posterior longitudinal ligament using micro-focus X-ray CT scanning and histological examination," Diagnostic Pathology, vol. 10, no. 1, article no. 205, 2015.

[24] Y. Nihon-Yanagi, T. Ishiwatari, Y. Otsuka et al., "A case of postoperative hepatic granuloma presumptively caused by surgical staples/clipping materials," Diagnostic Pathology, vol. 10, no. 1, article no. 90, 2015.

[25] Y. Kurosaka, Y. Shiroya, H. Yamauchi et al., "Effects of habitual exercise and dietary restriction on intrahepatic and periepididymal fat accumulation in Zucker fatty rats," BMC Research Notes, vol. 8, no. 1, article no. 121, 2015.

[26] K. Aki, Y. Okubo, H. Nanjo et al., "Genomic analysis of single nucleotide polymorphisms Asp299Gly and Thr399Ile in Japanese patients with invasive aspergillosis," Japanese Journal of Infectious Diseases, vol. 68, no. 4, pp. 330-332, 2015.

[27] T. Ishiwatari, Y. Okubo, N. Tochigi et al., "Remodeling of the pulmonary artery induced by metastatic gastric carcinoma: a histopathological analysis of 51 autopsy cases," BMC Cancer, vol. 14, no. 1, article no. 14, 2014.

[28] K. Y. Won, G. Y. Kim, Y. W. Kim, J. Y. Song, and S.-J. Lim, “Clinicopathologic correlation of beclin-1 and bcl-2 expression in human breast cancer," Human Pathology, vol. 41, no. 1, pp. 107112, 2010. 


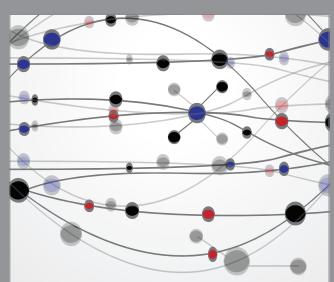

The Scientific World Journal
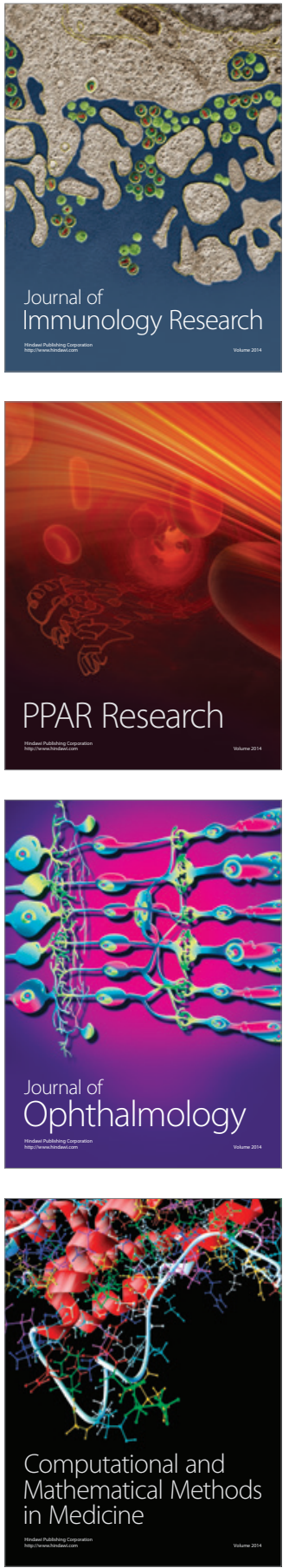

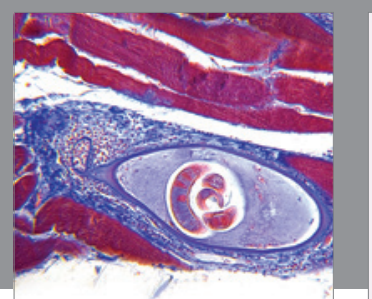

Gastroenterology Research and Practice

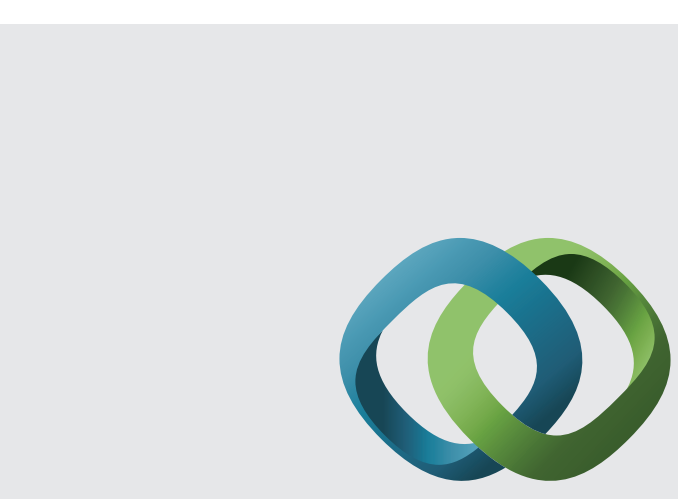

\section{Hindawi}

Submit your manuscripts at

http://www.hindawi.com
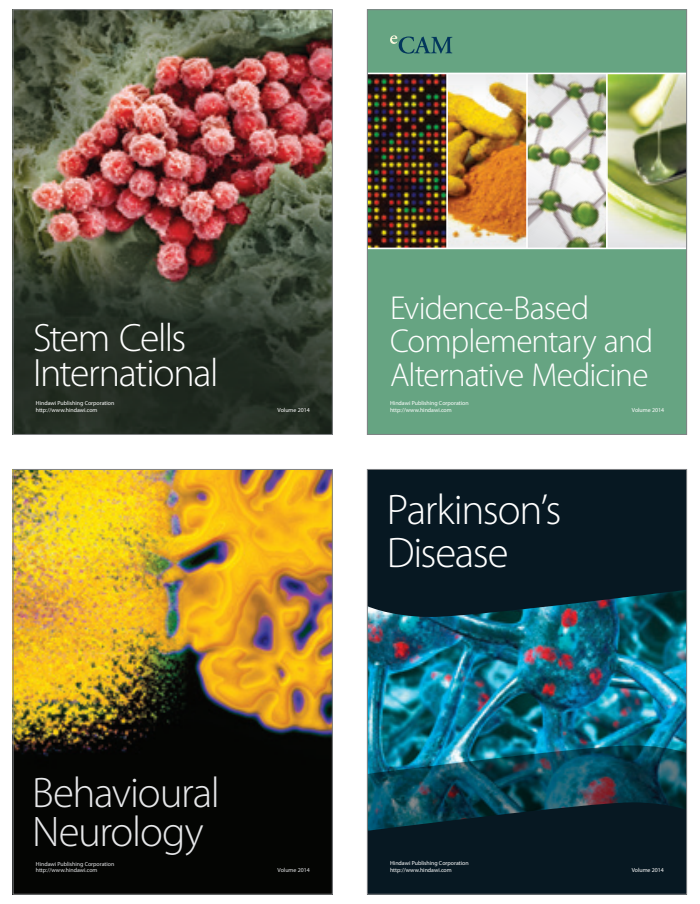
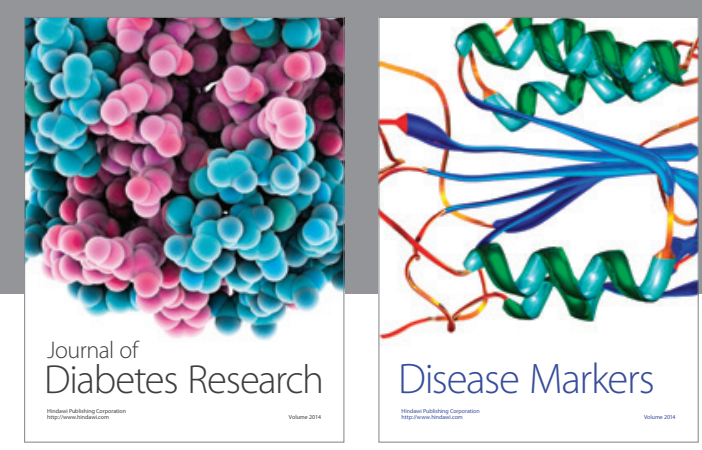

Disease Markers
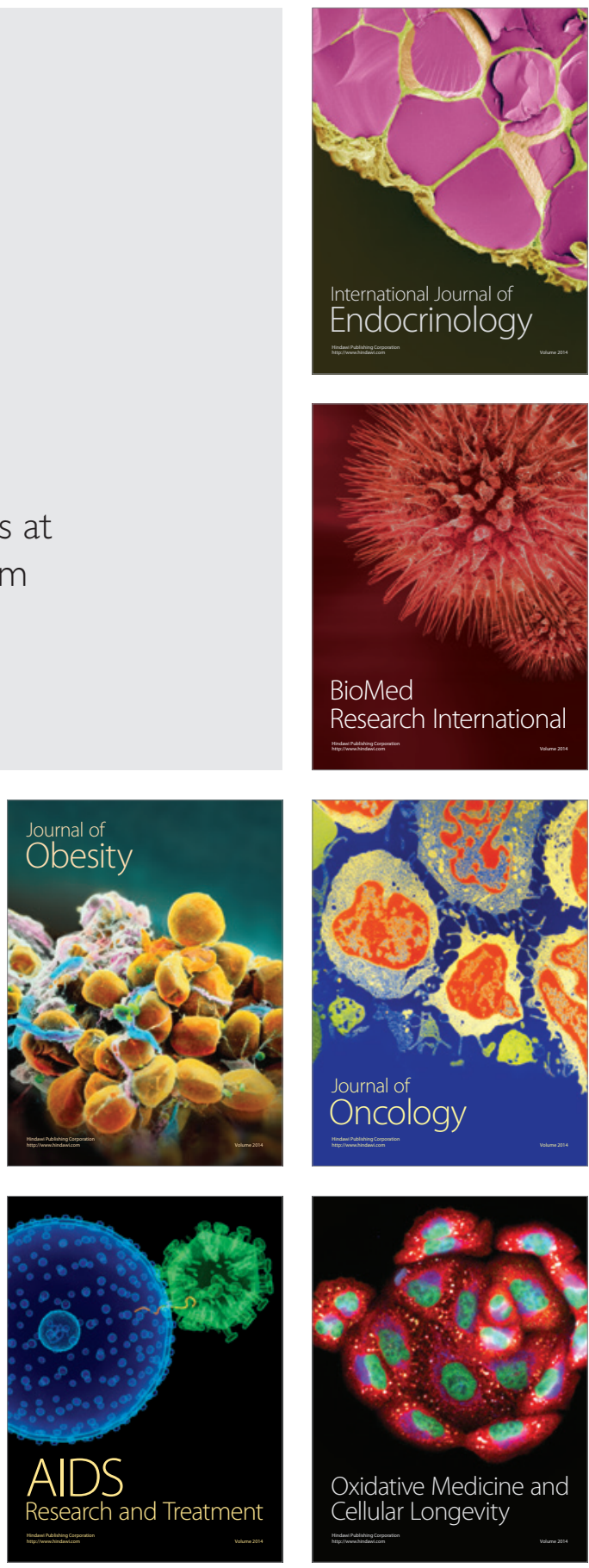